\title{
Investigation of the pro-apoptotic effects of arbutin and its acetylated derivative on murine melanoma cells
}

\author{
LIYAN JIANG $^{1,2}$, DI WANG ${ }^{2}$, YONGFENG ZHANG ${ }^{2}$, JUNYANG LI ${ }^{2}$, ZHIPING WU ${ }^{2}$, ZHI WANG ${ }^{1,2}$ and DI WANG ${ }^{1,2}$ \\ ${ }^{1}$ Laboratory of Molecular Enzymology and Engineering of Ministry of Education, \\ ${ }^{2}$ School of Life Sciences, Jilin University, Changchun, Jilin 130012, P.R. China
}

Received March 22, 2016; Accepted October 27, 2017

DOI: $10.3892 / \mathrm{ijmm} .2017 .3256$

\begin{abstract}
Arbutin, a natural polyphenol isolated from the bearberry plant Arctostaphylos uvaursi, possesses whitening and anticancer properties. The effects of arbutin on melanogenesis and its pro-apoptotic effect on B16 murine melanoma cells have not yet been reported. In the present study, acetylated arbutin was prepared in order to improve the biological effects of arbutin, and it was found to significantly inhibit the biosynthesis of melanin and tyrosinase activity compared with parent arbutin in B16 murine melanoma cells. Interestingly, only acetylated arbutin strongly inhibited B16 murine melanoma cell migration in a dose-dependent manner. Both arbutin and acetylated arbutin significantly reduced cell viability, promoted cell apoptosis, caused G1 cell cycle arrest and induced mitochondrial disruption in B16 murine melanoma cells. Furthermore, reduced expression of B-cell lymphoma-extra large (Bcl-xL) and $\mathrm{Bcl}-2$ were observed in arbutin- and acetylated arbutin-treated cells. Therefore, arbutin and acetylated arbutin were found to exert pro-apoptotic effects on B16 murine melanoma cells, mediated through the mitochondrial pathway. The findings of the present study also support the use of acetylated arbutin as a new potential candidate agent for skin whitening and melanoma treatment.
\end{abstract}

\section{Introduction}

Plant polyphenols are natural compounds that are widely distributed in plants and have been reported to possess antioxidant, antitumor and antiaging properties (1). However, the potential application of plant polyphenols is rather limited, due to their low bioavailability caused by poor cell membrane penetration (2). It was recently reported that acylation enhances biological activity, possibly due to the improvement of membrane penetration (3). Acetylated (-)-epigallocate-

Correspondence to: Dr Di Wang, School of Life Sciences, Jilin University, 2699 Qianjin Street, Changchun, Jilin 130012, P.R.China Email: wangzhi@jlu.edu.cn

Key words: arbutin, acetylated derivative, melanin, apoptosis, mitochondria
chin-3-O-gallate, isovitexin and isoorientin exhibited greater lipophilicity compared with their precursors (4). The enzymatic acylation of isoquercitrin and isorhamnetin-3-O-glucoside has been found to improve their antiproliferative effect on Caco-2 cancer cells $(5,6)$. Additionally, the acetylated quercetin ester exhibited marked antiproliferative activity against human cervical cancer cells and murine fibroblast NIH-3T3 cells (7).

Arbutin (hydroquinone-O- $\beta$-D-glucopyranoside), a natural polyphenol isolated from the bearberry plant Arctostaphylos uvaursi, has been traditionally used as a whitening agent $(8,9)$. Arbutin has been found to reduce the melanin content and tyrosinase activity in cultured human melanocytes, B16 murine melanoma cells and HMV-II cells (10-14). It has been reported that certain arbutin derivatives exert more prominent inhibitory effects on melanin content and tyrosinase activity compared with those of arbutin $(12,15,16)$. Furthermore, arbutin has been confirmed to exert a pro-apoptotic effect on human bladder cancer TCCSUP and human melanoma A375 cells $(17,18)$. However, the effects of arbutin and its acetylated derivative on B16 murine melanoma cells have not yet been reported.

Apoptosis is a complex programmed cell death, manifesting as cell shrinkage, chromatin condensation and internucleosomal DNA fragmentation (19). Extrinsic and intrinsic pathways play important roles in cellular functions, and mitochondrial function is considered to be a therapeutic target for cancer treatment (20).

In the present study, acetylated arbutin was prepared in order to improve the biological effects of arbutin, and the effects of arbutin and its acetylated derivative on melanin synthesis, tyrosinase activity and apoptosis of B16 murine melanoma cells were investigated. Flow cytometry was used to detect the effects of arbutin and acetylated arbutin on cell cycle and apoptosis, and the wound healing assay was used to measure cell migration ability. The potential underlying mechanism was investigated by western blot analysis and fluorescence microscopy.

\section{Materials and methods}

Synthesis of acetylated arbutin. Arbutin was purchased from Wuhan Fude Chemical Co., Ltd. (Wuhan, China), and its acetylated derivative was first synthesized by our 


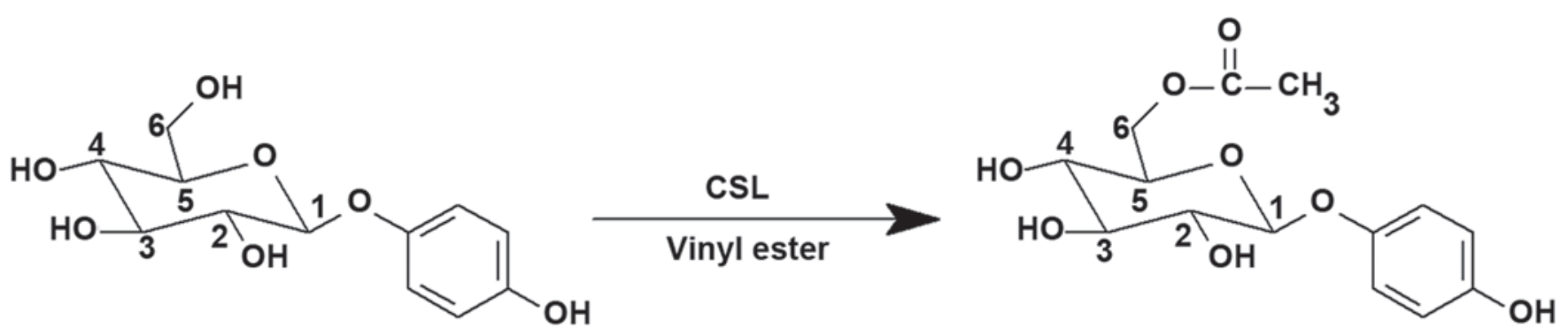

Figure 1. Procedure for preparation of acetylated arbutin. CSL, Candida sp.

laboratory (Fig. 1) (21). The reaction conditions were as follows: Arbutin $(0.73 \mathrm{mmol})$, vinyl acetate $(30 \mathrm{mmol})$, Candida sp. (CSL) (100 mg) and tetrahydrofuran (THF; $20 \mathrm{ml})$ were incubated with shaking $(100 \mathrm{rpm})$ at $40^{\circ} \mathrm{C}$ for $24 \mathrm{~h}$ [water activity $(\mathrm{aw})=0.63$ ]. The nuclear magnetic resonance $(\mathrm{NMR})$ analysis indicated that the C-6' position in the glucose moiety of arbutin was modified. The purity (>99\%) was confirmed by high-performance liquid chromatography.

Cell culture. The murine melanoma cells B16 (American Type Culture Collection, Manassas, VA, USA) were cultured in complete RPMI-1640 medium with $10 \%$ (v/v) inactivated fetal bovine serum, penicillin $\mathrm{G}$ and streptomycin $(100 \mathrm{mg} / \mathrm{l})$ at $37^{\circ} \mathrm{C}$ in $5 \% \mathrm{CO}_{2}$. All the agents for cell culture were obtained from Gibco, Thermo Fisher Scientific (Grand Island, NY, USA).

Cell viability assay. A total of $5 \times 10^{3}$ cells per well were plated onto 96-well plates, and various doses of arbutin and its acetylated derivative were added into each well, stimulating the cells for 24,48 or $72 \mathrm{~h}$. A total of $20 \mu \mathrm{l}$ of 3-(4,5-dimethylthiazol-2-yl)-2, 5-diphenyltetrazoliumbromide (MTT; Amresco, Solon, OH, USA) solution $(5 \mathrm{mg} / \mathrm{ml})$ was added to each well and then removed after a 4 -h incubation at $37^{\circ} \mathrm{C}$ in the dark. Purple formazan crystals were dissolved in $150 \mu$ l dimethylsulfoxide (DMSO) and quantitatively detected by measuring the absorbance at $540 \mathrm{~nm}$ using a microplate reader (F200 pro; Bio-Rad, Hercules, CA, USA). Each test was performed in quadruplicate, and each experiment was repeated twice.

Melanin content assay. The melanin content was measured as previously described, with minor modifications (22). B16 cells were seeded at a density of $5 \times 10^{5}$ cells per well in 6 -well plates and incubated for $24 \mathrm{~h}$. After treatment with arbutin and its acetylated derivative for $48 \mathrm{~h}$, the cells were washed with phosphate-buffered saline (PBS) and incubated with $1 \mathrm{M} \mathrm{NaOH}$ containing $1 \% \mathrm{DMSO}$ at $37^{\circ} \mathrm{C}$ for $1 \mathrm{~h}$. After dilution with $400 \mu \mathrm{l}$ distilled water, the absorbance at $490 \mathrm{~nm}$ was measured by a UV-2700 spectrophotometer (Shimadzu Corp., Kyoto, Japan).

Tyrosinase activity assay. Tyrosinase activity was measured based on a previously described method using L-DOPA as a substrate (23). A total of $5 \times 10^{5}$ cells were seeded into 6-well plates and incubated for $24 \mathrm{~h}$, and then treated with arbutin and its acetylated derivative. After $48 \mathrm{~h}$, the cells were washed with PBS and lysed with 1\% Triton X-100 (200 $\mu$ l). Cells were disrupted by repeated freezing and thawing, and then $100 \mu \mathrm{l}$ of the mixture and $50 \mu 10.5 \%$ L-DOPA were added into a 96-well plate at $37^{\circ} \mathrm{C}$ for $3 \mathrm{~h}$. The absorbance was measured at $490 \mathrm{~nm}$ by a spectrophotometer (Shimadzu Corp.).

Cell cycle and apoptosis analysis. Cell cycle and apoptosis were determined by flow cytometry (24). A total of $5 \times 10^{5}$ cells were seeded into 6-well plates and then treated with arbutin and its acetylated derivative. For cell cycle analysis, after $24 \mathrm{~h}$, the cells were harvested, fixed in ice-cold $70 \%$ ethanol and then stored at $4^{\circ} \mathrm{C}$ overnight. The cells were washed twice with PBS, suspended in $0.5 \mathrm{ml}$ of cold solution containing $25 \mathrm{~g} / \mathrm{ml}$ RNase A and $50 \mathrm{~g} / \mathrm{ml}$ propidium iodide (PI; Sigma-Aldrich, Merck KGaA, St. Louis, MO, USA), and incubated at $37^{\circ} \mathrm{C}$ for an additional $30 \mathrm{~min}$ in the dark. For cell apoptosis analysis, the cells were harvested, washed with cold PBS twice, and resuspended in binding buffer according to the manufacturer's protocol. Cells were then incubated with $5 \mu \mathrm{l}$ Annexin V-fluorescein isothiocyanate (FITC) and $10 \mu 1$ PI $(50 \mu \mathrm{g} / \mathrm{ml})$ (Becton Dickinson, Miami, FL, USA) mixed and incubated at room temperature for $10 \mathrm{~min}$ in the dark. The cell cycle and apoptosis were determined by analyzing 15,000 ungated cells using FACSCalibur (BD Biosciences, Mountain View, CA, USA) and Cell Quest software (Becton-Dickinson).

Migration assay. The wound healing assay was performed to evaluate the effect of arbutin and its acetylated derivative on the migration of B16 cells (25). A total of $5 \times 10^{5}$ cells were seeded into a 6-well plate and incubated for $24 \mathrm{~h}$. The cell monolayer was subjected to a mechanical scratch wound using a syringe needle, and then treated with arbutin and its acetylated derivative for $48 \mathrm{~h}$. Digitized images of the wound area were captured with BioTek Cytation ${ }^{\mathrm{TM}} 3$ Cell Imaging Multi-Mode Reader (BioTek Instruments Inc., Winooski, VT, USA). The width of the wound was expressed as a percentage of the control group.

Assessment of mitochondrial membrane potential (MMP). Cells were incubated with arbutin and its acetylated derivative for $24 \mathrm{~h}$, and then incubated with $2 \mu \mathrm{M}$ 5,5',6,6'-tetrachloro1,1',3,3'-tetraethylbenzimidazolylcarbocyanine iodide (JC-1; Sigma-Aldrich, Merck KGaA) at $37^{\circ} \mathrm{C}$ for $5 \mathrm{~min}$ in the dark. Following three washes with PBS, the changes in fluorescent color were examined using a fluorescence microscope (magnification, x20; CCD camera, TE2000; Nikon, Tokyo, Japan). The mean ratio of red $(590 \mathrm{~nm})$ to green $(540 \mathrm{~nm})$ fluorescent intensity of each cell in different groups was 



Figure 2. Inhibitory effect of (A) arbutin and (B) acetylated arbutin on cell viability. The cells were treated with various concentrations of arbutin and acetylated arbutin for 24,48 , or $72 \mathrm{~h}$, and cell viability was analyzed using the MTT assay. Data are expressed as a percentage of those from the corresponding control group and as means \pm standard deviation. $(\mathrm{n}=6) .{ }^{*} \mathrm{P}<0.05,{ }^{* *} \mathrm{P}<0.01$ and ${ }^{* * * *} \mathrm{P}<0.001$ vs. control cells.

calculated by Image $\mathbf{J}$ software (National Institutes of Health, Bethesda, WA, USA). The values of the treated cells were expressed as a percentage of those from the corresponding control cells.

Western blot analysis. The cells were seeded into 6-well plates at a density of $5 \times 10^{5}$ cells per well and treated with arbutin and its acetylated derivative for $24 \mathrm{~h}$. Treated cells were harvested, washed with cold PBS and lysed with RIPA buffer containing $1 \%$ protease inhibitor cocktail and $2 \%$ phenylmethanesulfonyl fluoride (all from Sigma-Aldrich, Merck KGaA). Protein concentration was measured using a bicinchoninic acid protein assay kit (Bio-Rad). A total of $30 \mu \mathrm{l}$ protein was separated using a 10-12\% SDS-PAGE gel and transferred electrophoretically onto PVDF membranes. The transferred membranes were blocked in 5\% bovine serum albumin for $4 \mathrm{~h}$, and then blotted with the following primary antibodies at $4^{\circ} \mathrm{C}$ overnight at dilution of 1:1,000: B-cell lymphoma (Bcl)-2, Bcl-xL and GAPDH (all from Cell Signaling Technology, Inc., Danvers, MA, USA). Binding was detected using an enhanced chemiluminescence kit (GE Healthcare, Buckinghamshire, $\mathrm{UK}$ ). The intensity of the bands was quantified by Image $\mathrm{J}$ software (National Institutes of Health).

Statistical analysis. Data were collected from at least three individual experiments for each assay and are presented as means \pm standard deviation. The difference between two independent samples was analyzed by a one-way analysis of variance to detect statistical significance followed by post-hoc multiple comparisons (Dunn's test) using SPSS 16.0 software (IBM corp., Armonk, NY, USA). P<0.05 was considered to indicate statistically significant differences.

\section{Results}

Antiproliferative activity of arbutin and acetylated arbutin. Arbutin and acetylated arbutin inhibited the viability of B16 murine melanoma cells in a time- and dose-dependent manner ( $\mathrm{P}<0.05$; Fig. 2). The $72 \mathrm{~h} \mathrm{IC}_{50}$ of the acetylated arbutin was $\sim 3.85 \mathrm{mM}$, which exhibited a higher efficacy in terms of cell proliferation compared with arbutin. Acetylated arbutin significantly inhibited melanogenesis up to $89.9 \%$ compared with the $45.8 \%$ inhibition by arbutin at $5.4 \mathrm{mM}(\mathrm{P}<0.05$; Fig. $3 \mathrm{~A})$. Tyrosinase is known to be the key enzyme in the process of melanin synthesis. Arbutin and acetylated arbutin at $5.4 \mathrm{mM}$ suppressed tyrosinase activity by 55.4 and $71.4 \%$, respectively, after a 48-h incubation ( $\mathrm{P}<0.01$; Fig. 3B).

The wound healing assay is considered to be an effective method for analysing cell migration (24). Comparatively, at the selected dose, only acetylated arbutin significantly suppressed the migration ability of B16 cells $(\mathrm{P}<0.05$; Fig. 4). Therefore, at the same dose, acetylated arbutin achieved a better effect compared with arbutin.

Arbutin and acetylated arbutin caused increased G1 cell cycle arrest compared with control cells (92.8 and 89.6 vs. $82.8 \%$, respectively) in B16 murine melanoma cells after $24 \mathrm{~h}$ of treatment, indicating their inhibitory activity on cell growth (Fig. 5).

Pro-apoptotic effects of arbutin and acetylated arbutin. The apoptosis rate following arbutin and acetylated arbutin treatment was detected by flow cytometry using Annexin V-FITC labeling for the detection of phosphatidylserine externalization, occurring as an early step during apoptosis. Compared with control cells (1.5\% of early apoptosis), arbutin and acetylated arbutin caused apoptosis in 19.3 and $23.7 \%$ of the cells, respectively, after $24 \mathrm{~h}$ of treatment at $5.4 \mathrm{mM}$ $(\mathrm{P}<0.001$; Fig. 6).

Arbutin and acetylated arbutin cause mitochondrial dysfunction. Mitochondria play a crucial role in regulating the intrinsic and extrinsic apoptotic pathways. Arbutin and acetylated arbutin caused marked MMP loss in B16 murine melanoma cells, as indicated by the augmentation in green fluorescence and the reduction in red fluorescence $(\mathrm{P}<0.001$; Fig. 7). Moreover, a striking reduction in $\mathrm{Bcl}-2$ and $\mathrm{Bcl}-\mathrm{xL}$ expression was noted in arbutin- and acetylated arbutin-treated cells $(\mathrm{P}<0.05$; Fig. 8). 
A

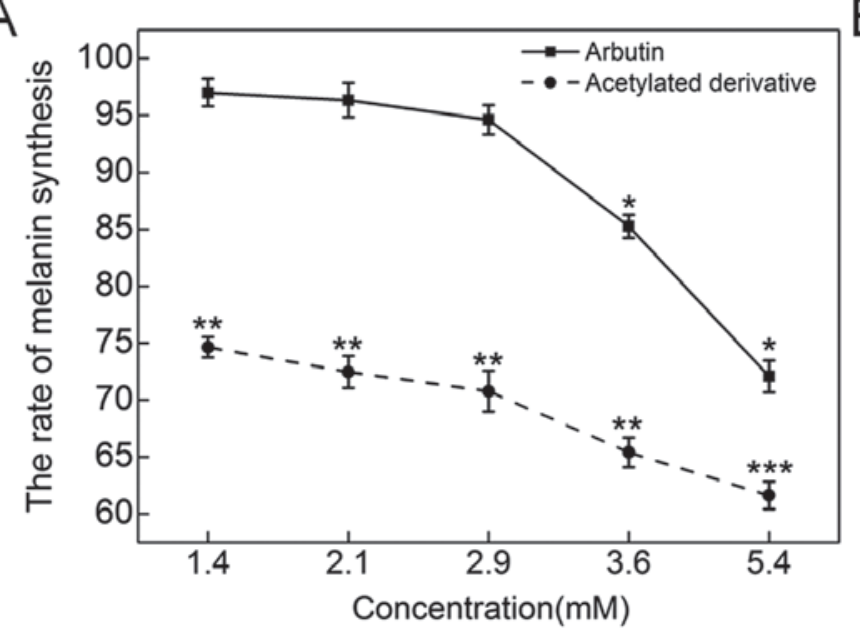



Figure 3. Effects of arbutin and acetylated arbutin on melanin synthesis (A) and tyrosinase activity (B) of B16 murine melanoma cells after 48 h treatment. Data are expressed as a percentage of that from corresponding control group and the means $\pm \mathrm{SD}(\mathrm{n}=6)$. ${ }^{*} \mathrm{P}<0.05$, ${ }^{* *} \mathrm{P}<0.01$ and ${ }^{* * * *} \mathrm{P}<0.001$ vs. control cells.
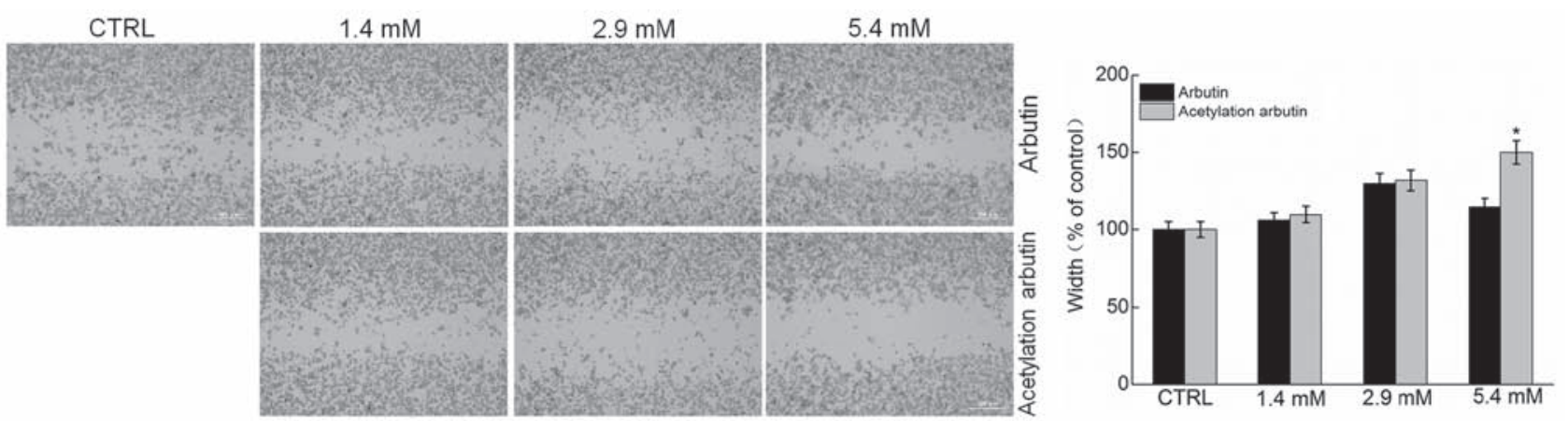

Figure 4. Arbutin and acetylated arbutin suppressed the migration ability of B16 murine melanoma cells, as determined via a wound healing assay (magnification, $\mathrm{x} 10$; scale bar, $300 \mu \mathrm{m})$. Data are expressed as mean \pm standard deviation $(\mathrm{n}=3)$. ${ }^{*} \mathrm{P}<0.05$ vs. control cells. CTRL, control.

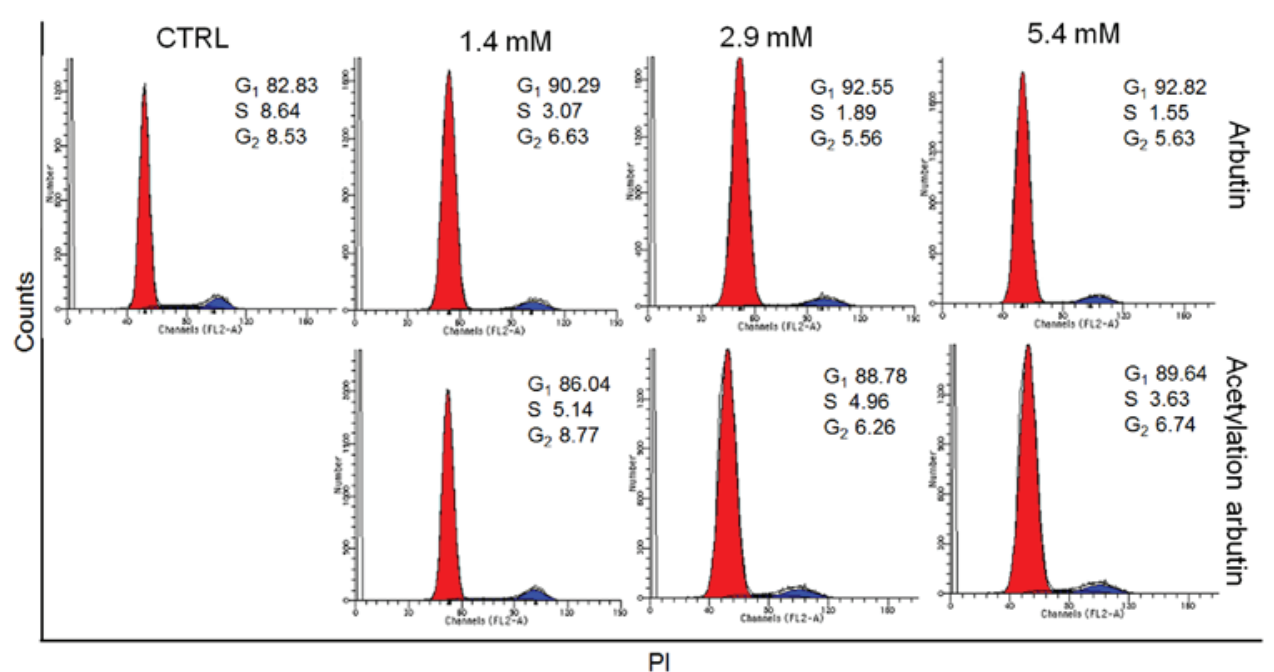

Figure 5. Arbutin and acetylated arbutin caused G1 cell cycle arrest in B16 murine melanoma cells after a $24 \mathrm{~h}$ treatment at a dose of $5.4 \mathrm{mM}$, as analyzed via flow cytometry $(\mathrm{n}=3)$. CTRL, control.

\section{Discussion}

The accumulation of melanin pigment has become a major cosmetic concern in humans. Arbutin, a naturally occurring hydroquinone that has a similar structure to the substrate that causes inhibition of tyrosinase, has been widely used in Japan $(26,27)$.Tyrosinase is a multifunctional copper-containing polyphenol oxidative enzyme, considered to be a key enzyme 

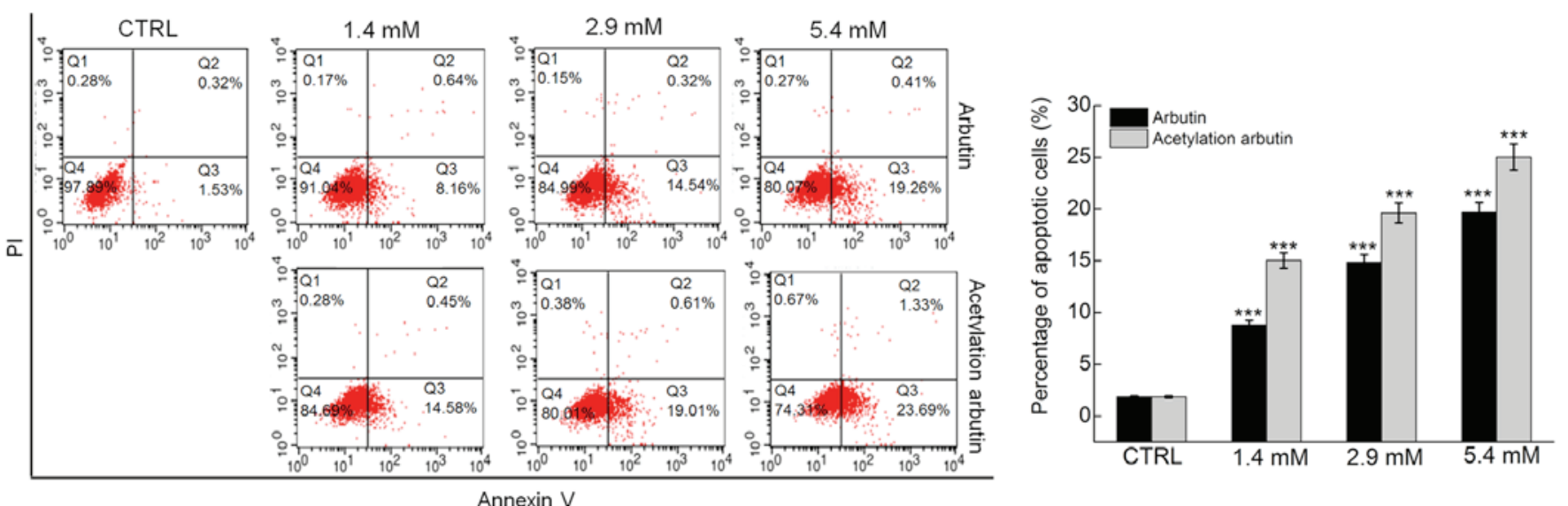

Figure 6. Arbutin and acetylated arbutin increased the apoptosis rate of B16 murine melanoma cell after $24 \mathrm{~h}$ of treatment at a dose of $5.4 \mathrm{mM}$, as analyzed via flow cytometry $(\mathrm{n}=3)$. Data are expressed as a percentage of apoptotic cells and mean \pm standard deviation $(\mathrm{n}=3) .{ }^{* * * *} \mathrm{P}<0.001 \mathrm{vs}$. control $(\mathrm{CTRL})$ cells.


Figure 7. Arbutin and acetylated arbutin caused the dissipation of MMP after $24 \mathrm{~h}$ of treatment at a dose of $5.4 \mathrm{mM}$, as detected by JC-1 staining and quantified as the ratio of red to green fluoresence intensity via Image $\mathbf{J}$ software (magnification, $\mathrm{x} 20$; scale bar, $100 \mu \mathrm{m})(\mathrm{n}=3)$. Data are expressed as mean \pm standard deviation $(\mathrm{n}=3) .{ }^{* * * *} \mathrm{P}<0.001$ vs. control cells. MMP, matrix mettaloproteinase; CTRL, control.

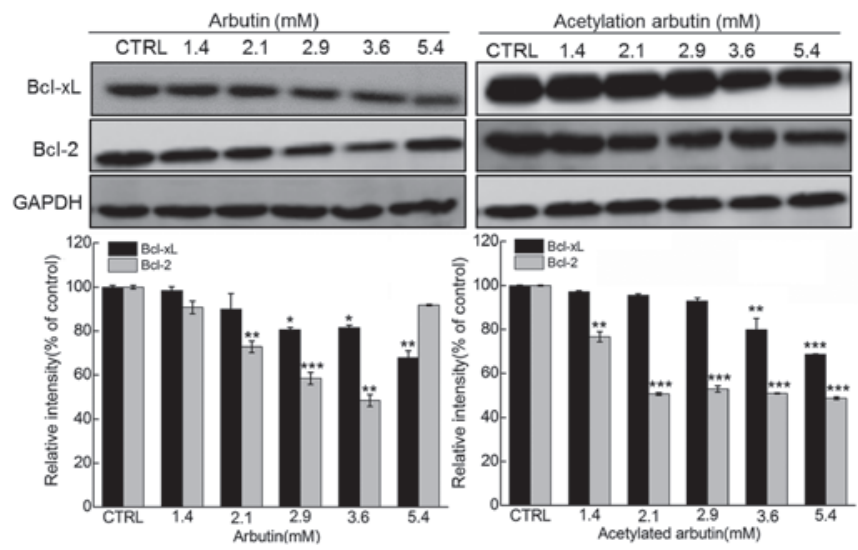

Figure 8. Arbutin and acetylated arbutin significantly reduced the expression of Bcl-2 and Bcl-xL in B16 murine melanoma cells after $24 \mathrm{~h}$ of treatment, as analyzed via western blotting $(\mathrm{n}=3)$. Quantification data were normalized against GAPDH expression, and expressed as a percentage of those from corresponding control cells. Data are expressed as mean \pm standard deviation $(\mathrm{n}=3)$ and analyzed using one-way analysis of variance. ${ }^{*} \mathrm{P}<0.05,{ }^{* * *} \mathrm{P}<0.01$ and ${ }^{* * * *} \mathrm{P}<0.001$ vs. control cells. GAPDH, glyceraldehyde 3-phosphate dehydrogenase; Bcl-2, B-cell lymphoma 2; Bcl-xL, B-cell lymphoma-extra large; CTRL, control.

in melanin biosynthesis and melanization in animals. The inhibition of tyrosinase activity is an important target for the treatment of pigmentation disorders (28). Several derivatives of arbutin have been synthesized, including deoxy-arbutin, in 
an attempt to overcome the limitation of penetration through the skin (29). Acetylated derivatives of arbutin exhibit higher antimelanogenetic and antityrosinase activity compared with the parent compound. An arbutin derivative caused a 50\% higher inhibition of tyrosinase activity, compared with free arbutin at the same concentration (30). Following incubation with arbutin 6'-undecenoate, melanin production decreased by $\sim 70 \%$ in B16 melanoma cells compared with that in control cells (31). In the present study, the acetylated arbutin derivative exhibited a higher efficacy in terms of tyrosinase activity inhibition and reduction of melanin production compared with arbutin, which may be associated with the increased solubility in oil-based systems and the improvement of membrane penetration (10-12).

Arbutin has also been reported to exert inhibitory effects on the proliferation of cancer cells, including A375 human malignant melanoma cells (17) and HCT-15 human TCCSUP cells (18). Our study demonstrated that arbutin and its acetylated derivative reduced cell viability, inhibited cell migration, enhanced apoptotic rate, caused G1 phase arrest and induced mitochondrial disruption in B16 melanoma cells. Accumulating evidence has confirmed the mitochondrial role in cell apoptosis (32), which may serve as a target for cancer treatment. The mitochondrial pathway is regulated by the Bcl-2 family of anti-apoptotic proteins, including Bcl-2 and Bcl-xL, and the pro-apoptotic proteins (33). The anti-apoptotic proteins regulate apoptosis by blocking the release of mitochondrial molecules, whereas imbalances in the expression of Bcl-2 family proteins, particularly the $\mathrm{Bcl}-2$ and Bax proteins, lead to permeabilization of the mitochondrial outer membrane followed by release of proteins, such as cytochrome c, from mitochondria to the cytoplasm, which may play an important role in subsequent cell death (34). Arbutin and its acetylated derivative decreased the expression of Bcl-2 and Bcl-xL, indicating that the mitochondrial apoptotic pathway may be involved in this pro-apoptotic effect.

It has been reported that oxidative stress induces apoptosis through DNA damage and mitochondrial dysfunction $(35,36)$. Arbutin exerts strong antioxidant effects, comparable or even superior to that of its precursor, hydroquinone, as skin-lightening agent. Arbutin protects U973 cells from radiation-induced apoptosis by decreasing intracellular hydroxyl radical production (37). Although our data indicated that the mitochondrial apoptotic pathway is responsible for arbutin and its acetylated derivative causing cell apoptosis, the precise role of the oxidative system requires further investigation.

In summary, arbutin and its acetylated derivative markedly reducing melanin content, suppressed tyrosinase activity and induced apoptosis in B16 melanoma cells, which may be mediated through modulation on the mitochondrial apoptotic pathway. It was also revealed that acetylated arbutin exhibited a higher efficacy compared with that of parent arbutin. Additionally, the control of melanin formation is crucial for the treatment of abnormal skin pigmentation, which may increase the risk of malignant melanoma. Tyrosinase is a key enzyme in melanin biosynthesis and its expression is closely correlated with melanogenesis (28). Therefore, arbutin and acetylated arbutin may be potential candidates not only for skin whitening, but also for the treatment of malignant melanoma.

\section{Acknowledgements}

The present study was supported by grants from the National Natural Science Foundation of China (nos. 21172093, 31070708,81402955 and 21072075), the Special Fund for Basic Scientific Research of Jilin University (nos. 450060326007 and 450060491559), the Scientific Research Project of Liaoning Educational Committee (no. L2012431), and the Natural Science Foundation of Jilin Province in China (nos. 20140101141JC and 201115038).

\section{References}

1. Yazaki K, Sasaki K and Tsurumaru Y: Prenylation of aromatic compounds, a key diversification of plant secondary metabolites. Phytochemistry 70: 1739-1745, 2009.

2. Yang RL, Li N, Li RF, Smith TJ and Zong MH: A highly regioselective route to arbutin esters by immobilized lipase from Penicillium expansum. Bioresour Technol 101: 1-5, 2010.

3. Trier S, Linderoth L, Bjerregaard S, Andresen TL and Rahbek UL: Acylation of Glucagon-like peptide-2: Interaction with lipid membranes and in vitro intestinal permeability. PLoS One 9: e109939, 2014.

4. Ma X, Yan R, Yu S, Lu Y, Li Z and Lu H: Enzymatic acylation of isoorientin and isovitexin from bamboo-leaf extracts with fatty acids and antiradical activity of the acylated derivatives. J Agric Food Chem 60: 10844-10849, 2012.

5. Salem JH, Humeau C, Chevalot I, Harscoat-Schiavo C, Vanderesse R, Blanchard F and Fick M: Effect of acyl donor chain length on isoquercitrin acylation and biological activities of corresponding esters. Process Biochem 45: 382-389, 2010.

6. Salem JH, Chevalot I, Harscoat-Schiavo C, Paris C, Fick M and Humeau C: Biological activities of flavonoids from Nitraria retusa (Forssk.) Asch and their acylated derivatives. Food Chem 124: 486-494, 2011.

7. Danihelová M, Veverka M, Sturdík E and Jantová S: Antioxidant action and cytotoxicity on HeLa and NIH-3T3 cells of new quercetin derivatives. Interdiscip Toxicol 6: 209-216, 2013.

8. Sakuma K, Ogawa M, Sugibayashi K, Yamada K and Yamamoto K: Relationship between tyrosinase inhibitory action and oxidation-reduction potential of cosmetic whitening ingredients and phenol derivatives. Arch Pharm Res 22: 335-339, 1999.

9. Hu ZM, Zhou Q, Lei TC, Ding SF and Xu SZ: Effects of hydroquinone and its glucoside derivatives on melanogenesis and antioxidation: Biosafety as skin whitening agents. J Dermatol Sci 55: 179-184, 2009.

10. Tomita Y, Maeda K and Tagami H: Melanocyte-stimulating properties of arachidonic acid metabolites: possible role in postinflammatory pigmentation. Pigment cell research/sponsored by the European Society for Pigment Cell Research and the International Pigment Cell Society 5: 357-361, 1992.

11. Nakajima M, Shinoda I, Fukuwatari Y and Hayasawa H: Arbutin increases the pigmentation of cultured human melanocytes through mechanisms other than the induction of tyrosinase activity. Pigment cell research/sponsored by the European Society for Pigment Cell Research and the International Pigment Cell Society 11: 12-17, 1998.

12. Sugimoto K, Nishimura T, Nomura K, Sugimoto K and Kuriki T: Inhibitory effects of alpha-arbutin on melanin synthesis in cultured human melanoma cells and a three-dimensional human skin model. Biol Pharm Bull 27: 510-514, 2004.

13. Akiu S, Suzuki Y, Asahara T, Fujinuma Y and Fukuda M: Inhibitory effect of arbutin on melanogenesis-biochemical study using cultured B16 melanoma cells. Nihon Hifuka Gakkai Zasshi 101: 609-613, 1991.

14. Maeda K and Fukuda M: In vitro effectiveness of several whitening cosmetic components in human melanocytes. J Soc Cosmet Chem 42: 261-268, 1991.

15. Sugimoto K, Nishimura T, Nomura K, Sugimoto K and Kuriki T: Syntheses of arbutin-alpha-glycosides and a comparison of their inhibitory effects with those of alpha-arbutin and arbutin on human tyrosinase. Chem Pharm Bull (Tokyo) 51: 798-801, 2003.

16. Sugimoto K, Nomura K, Nishimura T, Kiso T, Sugimoto K and Kuriki T: Syntheses of alpha-arbutin-alpha-glycosides and their inhibitory effects on human tyrosinase. J Biosci Bioeng 99: 272-276, 2005. 
17. Cheng SL, Liu RH, Sheu JN, Chen ST, Sinchaikul S and Tsay GJ: Toxicogenomics of A375 human malignant melanoma cells treated with arbutin. J Biomed Sci 14: 87-105, 2007.

18. Li H, Jeong YM, Kim SY, Kim MK and Kim DS: Arbutin inhibits TCCSUP human bladder cancer cell proliferation via up-regulation of p21. Pharmazie 66: 306-309, 2011.

19. Reed JC: Dysregulation of apoptosis in cancer. J Clin Oncol 17: 2941-2953, 1999.

20. Kurokawa M and Kornbluth S: Caspases and kinases in a death grip. Cell 138: 838-854, 2009.

21. Jiang L, Xie X, Yue H, Wu Z, Wang H, Yang F, Wang L and Wang Z: Highly efficient and regioselective acylation of arbutin catalyzed by lipase from Candida sp. Process Biochem 50: 789-792, 2015

22. Fujii T and Saito M: Inhibitory effect of quercetin isolated from rose hip (Rosa canina L.) against melanogenesis by mouse melanoma cells. Biosci Biotechnol Biochem 73: 1989-1993, 2009.

23. Kubo I, Nitoda T and Nihei K: Effects of quercetin on mushroom tyrosinase and B16-F10 melanoma cells. Molecules 12: 1045-1056, 2007.

24. Zhang J, Wu D, Xing Z, Liang S, Han H, Shi H, Zhang Y, Yang Y and Li Q: N-Isopropylacrylamide-modified polyethyleniminemediated p53 gene delivery to prevent the proliferation of cancer cells. Colloids Surf B Biointerfaces 129: 54-62, 2015.

25. Xing Z, Gao S, Duan Y, Han H, Li L, Yang Y and Li Q: Delivery of DNAzyme targeting aurora kinase A to inhibit the proliferation and migration of human prostate cancer. Int J Nanomedicine 10 $5715-5727,2015$

26. Maeda K and Fukuda M: Arbutin: Mechanism of its depigmenting action in human melanocyte culture. J Pharmacol Exp Ther 276: 765-769, 1996.

27. Hori I, Nihei K and Kubo I: Structural criteria for depigmenting mechanism of arbutin. Phytother Res 18: 475-479, 2004.

28. Kang KH, Lee B, Son S, Yun HY, Moon KM, Jeong HO, Kim DH, Lee EK, Choi YJ, Kim H, et al: (Z)-2-(Benzo[d] thiazol-2-ylamino)-5-(substituted benzylidene)thiazol-4(5H)-one Derivatives as Novel Tyrosinase Inhibitors. Biol Pharm Bull 38: $1227-1233,2015$.
29. Yan Q, Cao R, Yi W, Yu L, Chen Z, Ma L and Song H: Synthesis and evaluation of 5-benzylidene(thio)barbiturate-beta-Dglycosides as mushroom tyrosinase inhibitors. Bioorg Med Chem Lett 19: 4055-4058, 2009.

30. Tokiwa Y, Kitagawa M and Raku T: Enzymatic synthesis of arbutin undecylenic acid ester and its inhibitory effect on mushroom tyrosinase. Biotechnol Lett 29: 481-486, 2007.

31. Tokiwa Y, Kitagawa M, Raku T, Yanagitani S and Yoshino K: Enzymatic synthesis of arbutin undecylenic acid ester and its inhibitory effect on melanin synthesis. Bioorg Med Chem Lett 17: 3105-3108, 2007.

32. Lee CS, Kim YJ, Lee MS, Han ES and Lee SJ: 18beta-Glycyrrhetinic acid induces apoptotic cell death in SiHa cells and exhibits a synergistic effect against antibiotic anti-cancer drug toxicity. Life Sci 83: 481-489, 2008.

33. Kang $\mathrm{MH}$ and Reynolds CP: Bcl-2 inhibitors: targeting mitochondrial apoptotic pathways in cancer therapy. Clin cancer res 15: 126-1132, 2009.

34. Kinnally KW and Antonsson B: A tale of two mitochondrial channels, MAC and PTP, in apoptosis. Apoptosis 12: 857-868, 2007.

35. Wochna A, Niemczyk E, Kurono C, Masaoka M, Kedzior J, Słomińska E, Lipiński M and Wakabayashi T: A possible role of oxidative stress in the switch mechanism of the cell death mode from apoptosis to necrosis--studies on rho0 cells. Mitochondrion 7: 119-124, 2007.

36. Denning TL, Takaishi H, Crowe SE, Boldogh I, Jevnikar A and Ernst PB: Oxidative stress induces the expression of Fas and Fas ligand and apoptosis in murine intestinal epithelial cells. Free Radic Biol Med 33: 1641-1650, 2002.

37. Wu LH, Li P, Zhao QL, Piao JL, Jiao YF, Kadowaki M and Kondo T: Arbutin, an intracellular hydroxyl radical scavenger, protects radiation-induced apoptosis in human lymphoma U937 cells. Apoptosis 19: 1654-1663, 2014. 